OPEN ACCESS

Edited by:

Enrico Baruffini,

University of Parma, Italy

Reviewed by:

Edward Quadros,

SUNY Downstate Medical Center.

United States

Irini Manoli,

National Institutes of Health (NIH),

United States

*Correspondence:

Wei Zhou

wei0743916@163.com

Specialty section: This article was submitted to

Genetic Disorders,

a section of the journal

Frontiers in Genetics

Received: 19 July 2018 Accepted: 22 December 2018

Published: 23 January 2019

Citation:

Zhou W, Li H, Wang C, Wang X and Gu M (2019) Newborn Screening

for Methylmalonic Acidemia in a

Chinese Population: Molecular Genetic Confirmation and Genotype

Phenotype Correlations.

Front. Genet. 9:726.

doi: 10.3389/fgene.2018.00726

\section{Newborn Screening for Methylmalonic Acidemia in a Chinese Population: Molecular Genetic Confirmation and Genotype Phenotype Correlations}

\author{
Wei Zhou*, Huizhong Li, Chuanxia Wang, Xiuli Wang and Maosheng Gu \\ Xuzhou Maternity and Child Health Care Hospital, Xuzhou, China
}

Background: Methylmalonic acidemia (MMA) incidence was evaluated based on newborn screening in Xuzhou from November 2015 to December 2017, and the clinical, biochemical and molecular characteristics of patients with MMA harboring MMACHC and MUT mutations were summarized.

Methods: During the study, 236,368 newborns were screened for MMA by tandem mass spectrometry (MS/MS) in the Maternity and Child Health Care Hospital of Xuzhou. C3, C3/C2 and methionine, and tHcy if necessary, were measured during the first screening. Blood samples from the infants and/or their family members were used for DNA analysis. The entire coding regions of the MMACHC and MUT genes associated with MMA were sequenced by DNA MassARRAY and next-generation sequencing (NGS).

Results: Eleven patients with MMACHC mutations and three with MUT mutations were identified among the 236,368 screened newborns; the estimated total incidence of MMA was 1:16,883. Among the MMA patients, two died of infection-triggered metabolic crisis approximately 3 months after birth. All the patients identified had two mutant alleles except for one individual with early-onset disease. The most common MMACHC mutation was c.609G > A. The laboratory levels of C3 and C3/C2 were elevated in MMA individuals compared to other infants. Importantly, we demonstrate that accelerated C2 degradation is related to air temperature and humidity.

Conclusion: Our study reports the clinical characteristics of MMA and diagnosis through MS/MS and NGS. There was a higher incidence of MMA with homocysteinemia than of isolated MMA in Xuzhou. Insight from this study may help explain the high false-positive rate of MMA in summer.

Keywords: methylmalonic acidemia, newborn screening, MMACHC, MUT, MS/MS

\section{INTRODUCTION}

Methylmalonic acidemia (MMA) comprises a series of autosomal recessive inherited disorders of organic acid metabolism. The primary defect lies in methymalonyl-CoA mutase (MCM) or its cofactor, adenosylcobalamin (AdoCbl) (Han L. et al., 2015). MMA causes various clinical symptoms including recurrent vomiting, metabolic acidosis, and even developmental delay 
(Radmanesh et al., 2008). The cellular pathway in MMA by which cobalamin (OH-Cbl) is processed to AdoCbl and methylcobalamin (MeCbl) is depicted in Figure 1. The cobalamin-processing enzymes have been indicated to be causative factors (Obeid et al., 2015; Richard et al., 2018). MMA can be classified into two common types: isolated MMA and combined MMA and homocysteinemia, which are caused by deficiency in the MUT or MMACHC gene, respectively. In addition to the two above-mentioned MMA types, there are five other less common subtypes, including cblD, cblF, cblJ, and cblX deficiencies (Yu et al., 2013; Hu et al., 2018). Moreover, some other mutant genes associated with isolated MMA have also been verified including MMUT, MMAA, MMAB, MCEE, and MMADHC (Hörster et al., 2007; Ktena et al., 2015; Peng et al., 2018). The most common biochemical hallmark of these defects is the accumulation of methylmalonic acid and homocysteine in the blood and urine due to the dysfunction in $\mathrm{MeCbl}$ and AdoCbl (Carrillo-Carrasco et al., 2012; Huemer et al., 2014).

Isolated MMA is characterized by the abnormal accumulation of methylmalonic acid in metabolites without hyperhomocysteinemia. The MUT gene lies within chromosome 6 p12.3 and has 13 exons that encode 750 amino acids (Worgan et al., 2006). Approximately 250 mutations have been identified to date in the MUT gene in different populations. The clinical manifestations and biochemical parameters of isolated MMA patients commonly present during the first weeks and months after birth as poor feeding, recurrent vomiting, and severe metabolic acidosis.

Combined MMA and hyperhomocysteinemia, cblC type, is the most common inherited disorder of cobalamin metabolism, and the related gene, MMACHC, is located at 1p34.1 (WeisfeldAdams et al., 2013; Pastore et al., 2014). CblC disease patients usually exhibit systemic and neurological abnormalities in the neonatal period. Existing research recognizes the critical role of timely disease treatment.

Data obtained from various countries worldwide suggest that the estimated incidence of MMA ranges from 1:48,000 to 1: 250,000 (Weisfeld-Adams et al., 2013). Wang et al. (2010) reported the incidence of cblC disorder by newborn screening to be in the high range of 1: 3,920 for an ethnically diverse population in Shandong, China, contrasting with a previous estimate of 1:28,000 births by clinical ascertainment in Shanghai (Han et al., 2016). The introduction of an expanded screening program for newborns is recommended to identify those infants who are considered at risk for MMA. Now that an MMA diagnosis can be confirmed by DNA testing and gas chromatography/mass spectrometry (GC/MS) based urine analysis, it is possible to improve the outcome of newborn screening for MMA. With regards to the work conducted in our center, newborn screening for MMA began in November 2015 in Xuzhou, Jiangsu Province, China. We documented the clinical features and spectrum of gene mutations in 15 MUT and $M M A C H C$ patients and identified 14 mutations, including 5 MUT and 9 MMACHA mutations. We aimed to estimate the incidence of MMA during newborn screenings and to summarize the clinical features, molecular characteristics, treatment, and follow-ups of infants with MMA who received early treatment.

\section{PATIENTS AND METHODS}

\section{Study Population and MS/MS Newborn Screening}

From November 2015 to December 2017, 236,368 newborns were screened for PCD at the Genetic Medicine Center of the Maternity and Child Health Care Hospital in Xuzhou. Acylcarnitine concentrations were quantified by tandem mass spectrometry (MS/MS), with a quantify spot of $2 \mathrm{mg} / \mathrm{dL}(134 \mu \mathrm{mol} / \mathrm{L})$ for whole blood. The reference levels of propionylcarnitine (C3), C3/acetylcarnitine (C2), and methionine were measured. 52 among the 236,368 newborns were included in the recalling screening and 14 individuals were involved with confirmatory testing. Informed and written consent was obtained from the guardians of all the patients before clinical testing.

\section{DNA Sequencing and Diagnosis}

Blood samples from infants with an abnormal newborn screening and/or their family members were sent to Bioscan Genomics, Hangzhou. Subsequently, DNA was extracted from peripheral blood leukocytes using the OMEGA Genomic DNA Extraction Kit (OMEGA Biotech, United States). The targeted DNA sequence was mapped to and analyzed against a genetic diagnosis panel of inherited metabolic diseases associated with the MMACHC and MUT genes, including MMAA, MMAB, MMACHC, MUT, PCCA, and $P C C B$.

To further confirm the diagnosis, the levels of organic acids in the urine were measured with GC/MS. Moreover, the concentration of total plasma homocysteine (tHcy) was determined (Weisfeld-Adams et al., 2010). All tests were performed after informed consent was obtained from the guardians of all the patients.

\section{Treatment and Follow-Up}

The patients with clbC type disease were given hydroxocobalamin (OHCbl) (1-2 mg, two-three times weekly, intramuscular injection), levocarnitine (100 mg/kg/day, oral administration), betaine ( $250 \mathrm{mg} /$ day, oral administration), and folinic acid (5-15 mg/day, oral administration). Levocarnitine was administered in conjunction with restricted protein intake to most isolated MMA individuals in accordance with disease progression.

Outpatient clinical follow-up occurred once per month during the initial treatment, followed by once every 3 months or longer once stable conditions were achieved. Changes in MMA, C3, tHcy and methionine levels and mental development were monitored during treatment. Infants with MMA were followed up for 1.8 years after birth to the present.

\section{Statistical Analysis}

In the statistical analysis, $t$-tests were used to analyze the effects of changes in the experimental condition. A $P$-value $<0.05$ was considered significant. 


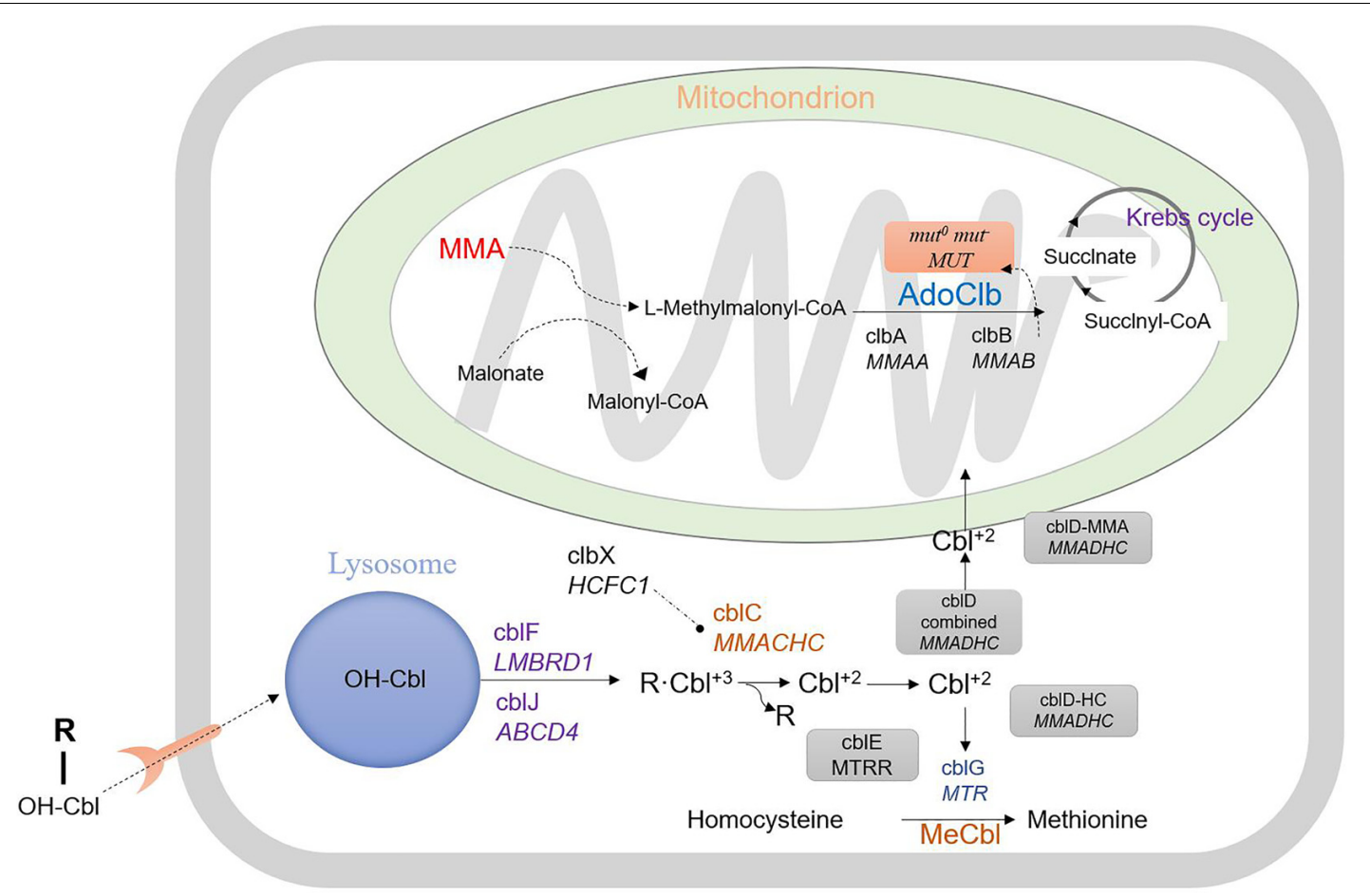

FIGURE 1 | Intracellular vitamin B12 (or cobalamin) metabolism.

\section{RESULTS}

\section{Clinical and Biochemical Description}

Fourteen patients were identified by screening 236,368 newborns, yielding an estimated MMA incidence of 1:16,883 live births, while the incidence of MMACHC cblC and isolated MUT MMA was $1: 19,697$ vs. $1: 78,789$, respectively. All the patients presented with elevated C3 levels ( $>5 \mu \mathrm{mol} / \mathrm{L}$ ), an increased $\mathrm{C} 3 / \mathrm{C} 2$ ratio $(>0.18)$, and low or normal methionine levels in dried blood spots (normal range $5-40 \mu \mathrm{mol} / \mathrm{L}$ ) (Tables 1, 3). It is worth mentioning that the reference interval was in accordance with the percentiles of 200,000 health screening samples in Xuzhou. Subsequently, the normal range of methionine was confirmed. Indeed, there exists a mild difference of the cut-off value worldwide (Weisfeld-Adams et al., 2010). In addition, the patients with clbC disease exhibited increased methylmalonic acid levels ( $>5 \mathrm{mg} / \mathrm{gCr}$ ) in the urine and elevated total plasma homocysteine $(>13.56 \mu \mathrm{mol} / \mathrm{L})$ (Table 1). 11 of the 14 individuals were diagnosed with combined MMA and hyperhomocysteinemia, and the diagnoses were confirmed by MMACHC gene sequencing. However, data about tHcy levels are limited and insufficient partly due to patient referral. Further work of data collection is being performed to confirm this finding. Another three patients, shown in Table 3, were diagnosed with isolated MMA at ages varying from 3 days to 4 weeks with DNA sequencing reports, while they were all received immediate intervention after newborn screening. As can be seen from Table 3, high levels of blood C3 and urinary MMA were detected. Taken together, the data showed that all three of these patients survived with developmental delay after receiving timely treatment after diagnosis.

Six patients started treatment immediately following confirmation of the clbC disease diagnosis. Unfortunately, case 3 died from metabolic crisis triggered by infection approximately 1 month after birth. Cases 9, 10, and 11 were lost to follow-up, most likely due to population mobility. The other patients are alive. Five patients (cases 2, 4, 5, 7, and 8) were treated with intramuscular hydroxocobalamin, levocarnitine, betaine and folinic acid (Table 2). Case 1 was treated similarly, to the above patients but without betaine. Case 12 was given intramuscular hydroxocobalamin alone (Table 2 ). All the patients who received treatment had a favorable metabolic response, with reduced urine MMA and tHcy and increased methionine (Table 2).

Although not all of the biochemical parameters reached the levels present in healthy individuals, laboratory values after treatment were lower than those found in individuals with earlyonset clbC. As shown in Figure 2, MMA in urine and total plasma homocysteine dramatically decreased after treatment. C3 in the blood declined but did not reach the normal range.

\section{MS/MS Biochemical Quantification for MMA}

Of the 236,368 newborns screened by MS/MS in our study, $52(0.02 \%)$ had $\mathrm{C} 3$ levels and a $\mathrm{C} 3 / \mathrm{C} 2$ ratio exceeding the cutoff values and were reported as screening positive for MMA. According to further diagnostic testing, cases of clbC disease with mutations in the MMACHC gene $(n=11)$, isolated MMA with mutations in the MUT gene $(n=3)$ and no mutations $(n=38)$ 
TABLE 1 | Biochemical data and DNA mutations features of eleven patients with MMACHC-type diagnosed on newborn screening.

\begin{tabular}{|c|c|c|c|c|c|c|c|c|c|c|}
\hline Case & Gender & $\begin{array}{l}\text { Age at } \\
\text { diagnosis } \\
\text { (time after birth) }\end{array}$ & $\begin{array}{c}\text { Birth } \\
\text { weight } \\
\text { (kg) }\end{array}$ & $\begin{array}{c}\text { C3 on } \\
\text { NBS } \\
(\mu \mathrm{mol} / \mathrm{L})\end{array}$ & $\begin{array}{c}\text { C3/C2 } \\
\text { ratio on } \\
\text { NBS }\end{array}$ & $\begin{array}{l}\text { Met on } \\
\text { NBS } \\
(\mu \mathrm{mol} / \mathrm{L})\end{array}$ & $\begin{array}{c}\text { Urine } \\
\text { MMA } \\
\text { (mg/gCr) }\end{array}$ & $\begin{array}{c}\text { THcy } \\
(\mu \mathrm{mol} / \mathrm{L})\end{array}$ & $\begin{array}{l}\text { MMACHC } \\
\text { genotype }\end{array}$ & $\begin{array}{l}\text { Variation in } \\
\text { protein level }\end{array}$ \\
\hline 1 & $\mathrm{~F}$ & 20 days & 3.75 & 4.04 & 0.24 & 7.40 & 158.74 & 89.60 & $\begin{array}{c}\text { c.482G > A/c.658_ } \\
\text { 660delAAG }\end{array}$ & $\begin{array}{l}\text { p.D77Qfs*22/ } \\
\text { p.K220del }\end{array}$ \\
\hline 2 & $\mathrm{M}$ & 24 days & 3.45 & 7.70 & 0.46 & 11.95 & 33.48 & 109.5 & $\begin{array}{c}\text { c. } 1 \text { A }>\text { G/c.658_ } \\
660 \text { delAAG }\end{array}$ & $\begin{array}{l}\text { p.M1V/ } \\
\text { p.K220del }\end{array}$ \\
\hline 3 & $\mathrm{~F}$ & 3 weeks & 2.50 & 5.21 & 1.57 & 4.71 & - & - & $\begin{array}{c}\text { c. } 276+1 \mathrm{G}>\mathrm{A} / \mathrm{c} .658 \text { _ } \\
\text { 660delAAG }\end{array}$ & //p.K220del \\
\hline 4 & $M$ & 20 days & 2.95 & 8.19 & 0.24 & 11.05 & 5.82 & 102.36 & $\begin{array}{c}\text { c.609G > A/c.228_ } \\
\text { 231delTGAC }\end{array}$ & $\begin{array}{c}\text { p.W203*/ } \\
\text { p.D77Qfs*22 }\end{array}$ \\
\hline 5 & $M$ & 15 days & 3.00 & 6.65 & 0.91 & 8.67 & 12.32 & 92.32 & $\begin{array}{l}\text { c.567dupT/ } \\
\text { c. } 80 A>G\end{array}$ & $\begin{array}{l}\text { p.I190Yfs*13/ } \\
\text { p.Q27R }\end{array}$ \\
\hline $6^{*}$ & $\mathrm{~F}$ & 10 days & 3.30 & 7.92 & 0.35 & 19.95 & 66.35 & - & c. $482 \mathrm{G}>\mathrm{A} /-$ & p.R161Q/- \\
\hline 7 & $\mathrm{~F}$ & 4 weeks & 1.95 & 6.57 & 0.38 & 9.89 & 163.84 & 41.99 & $\begin{array}{c}\text { c. } 609 \mathrm{G}>\mathrm{A} \\
\text { c.567dupT }\end{array}$ & $\begin{array}{c}\text { p.W203*/ } \\
\text { p.I190Yfs*13 }\end{array}$ \\
\hline 8 & $M$ & 20 days & 3.65 & 7.21 & 0.39 & 17.06 & 46.73 & 86.32 & $\begin{array}{l}\text { c. } 482 G>A \\
\text { c. } 609 G>A\end{array}$ & $\begin{array}{l}\text { p.R161Q/ } \\
\text { p.W203* }\end{array}$ \\
\hline 9 & $\mathrm{~F}$ & 24 days & 2.70 & 6.42 & 0.85 & 6.09 & 155.09 & - & $\begin{aligned} \text { c. } 609 G & >A \\
\text { c. } 609 G & >A\end{aligned}$ & $\begin{array}{l}\text { p.W203*/ } \\
\text { p.W203* }\end{array}$ \\
\hline 10 & M & 3 weeks & 3.80 & 8.05 & 0.43 & 16.79 & 21.22 & - & $\begin{aligned} \text { c. } 482 G & >A \\
\text { c. } 515 A & >G\end{aligned}$ & $\begin{array}{l}\text { p.R161Q/ } \\
\text { p.K172T }\end{array}$ \\
\hline 11 & $M$ & 18 days & 2.40 & 8.8 & 1.17 & 4.87 & 46.93 & - & $\begin{array}{l}\text { c.567dupT/ } \\
\text { c.609G > A }\end{array}$ & $\begin{array}{l}\text { p.l190Yfs*13/ } \\
\text { p.W203* }\end{array}$ \\
\hline
\end{tabular}

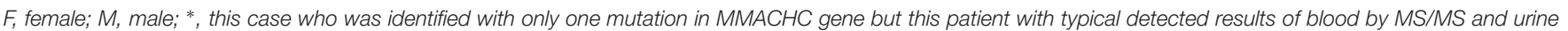

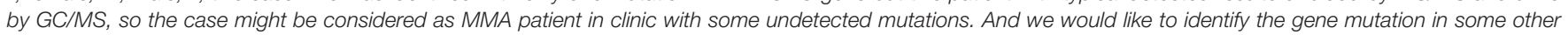
methods in the future. Age at diagnosis was identified with DNA reports.

TABLE 2 | Therapeutic regime, biochemical data and clinical features in patients with MMACHC-type after treatment.

\begin{tabular}{|c|c|c|c|c|c|c|c|c|c|}
\hline \multirow{2}{*}{$\begin{array}{l}\text { Case } \\
\text { number }\end{array}$} & \multicolumn{4}{|c|}{ Therapeutic regime } & \multirow{2}{*}{$\begin{array}{l}\text { Clinical development } \\
\text { estimation }\end{array}$} & \multicolumn{4}{|c|}{ Metabolic parameters at recent visit } \\
\hline & OHCbI IM & $\begin{array}{l}\text { L-carnitine } \\
\text { oral } \\
\text { (mg/kg/day) }\end{array}$ & $\begin{array}{c}\text { Betaine } \\
\text { oral } \\
\text { (mg/kg/day) }\end{array}$ & $\begin{array}{l}\text { Folinic } \\
\text { acid oral } \\
\text { (mg/day) }\end{array}$ & & $\begin{array}{c}\text { C3 } \\
(\mu \mathrm{mol} / \mathrm{L})\end{array}$ & $\begin{array}{l}\text { Urine MMA } \\
\text { (mg/gCr) }\end{array}$ & $\begin{array}{c}\text { THcy } \\
(\mu \mathrm{mol} / \mathrm{L})\end{array}$ & $\begin{array}{c}\text { Met } \\
(\mu \mathrm{mol} / \mathrm{L})\end{array}$ \\
\hline 1 & $1 \mathrm{mg}$, twice weekly & 100 & - & 7.5 & $\begin{array}{l}\text { Mild developmental } \\
\text { delay }\end{array}$ & 2.10 & 6.08 & 15.68 & 43.4 \\
\hline 2 & 1-2 mg, third weekly & 100 & 250 & 5 & Dead & 7.96 & 39.72 & - & 58.56 \\
\hline 4 & 1-2 mg, third weekly & 100 & 250 & 7.5 & $\begin{array}{l}\text { Severe developmental } \\
\text { delay }\end{array}$ & 6.61 & 29.41 & 11.66 & 21.19 \\
\hline 5 & 1-2 mg, third weekly & 100 & 250 & 7.5 & $\begin{array}{l}\text { Slight hypotonia, mild } \\
\text { developmental delay }\end{array}$ & 7.46 & 11.12 & 10.69 & 38.74 \\
\hline 7 & $1 \mathrm{mg}$, third weekly & 100 & 250 & 15 & developmental delay & 4.94 & 24.79 & 52.36 & 5.65 \\
\hline 8 & 1-2 mg, twice weekly & 100 & 250 & 7.5 & $\begin{array}{l}\text { Mild developmental } \\
\text { delay }\end{array}$ & 5.58 & 5.51 & 10.45 & 29.25 \\
\hline
\end{tabular}

PS, developmental delay for young children <4-6 years and intellectual impairment/disability for older children, while given the children are all <2 years old.

were then reported and treated in our center. Remarkably, to avoid misdiagnosis of other diseases associated with increased C3 in newborn screening, the 38 individuals with no MMA-related mutations underwent DNA sequencing analysis of a genetic diagnosis panel covering 51 diseases and 98 genes. After NGS and data analysis, it was possible to exclude these diseases. Then, these individuals were selected as the control group. However, further data collection is required to determine whether the laboratory results are due to other rare forms of MMA; almost all of the control individuals were followed up for a period after recalling, and the results were normal at the last follow-up. 2-Methylcitric acid (C2) was retrospectively measured in all positive infants $(n=52)$ and ranged from 1.2 to $38.12 \mu \mathrm{mol} / \mathrm{L}$. Table 4 shows the levels of $\mathrm{C} 2, \mathrm{C} 3$, and $\mathrm{C} 3 / \mathrm{C} 2$ in our study patients. As shown in Figure 3, $\mathrm{C} 3$ and $\mathrm{C} 3 / \mathrm{C} 2$ were primarily elevated in MMA patients, while $\mathrm{C} 2$ levels were not different between healthy and MMA newborns. The laboratory levels of $\mathrm{C} 3$ and $\mathrm{C} 3 / \mathrm{C} 2$ in newborns with early-onset MMA were above normal, as shown in Figure 3, but the distribution in the control group ranged both above and below normal. 

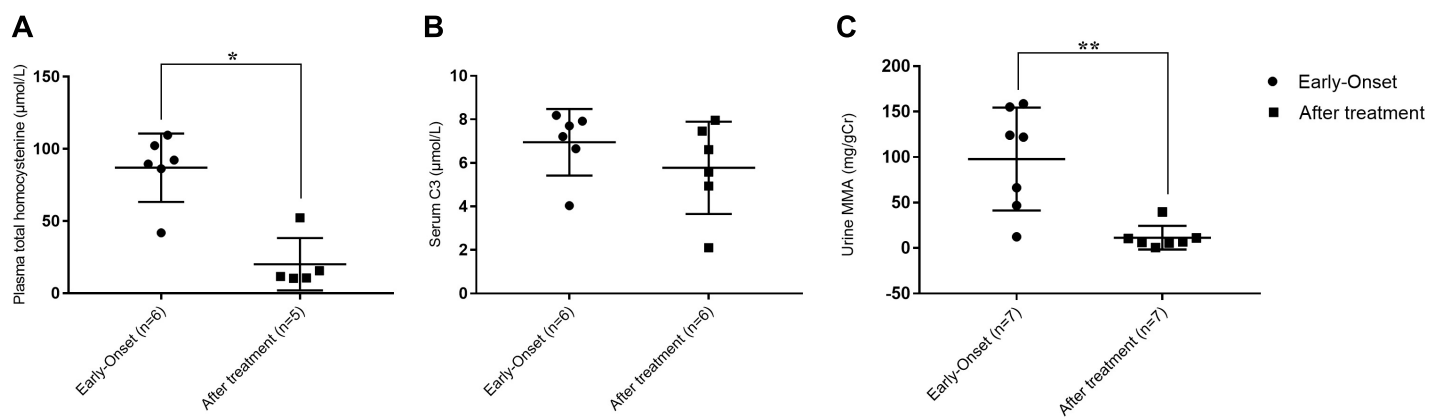

FIGURE 2 | Metabolite measurement of clbC patients. (A) Total homocysteine of plasma. (B) The level of C3. (C) The level of MMA in urine. ${ }^{*} P<0.05,{ }^{* *} P<0.01$.

TABLE 3 | Clinical characteristics of the MUT-type patients.

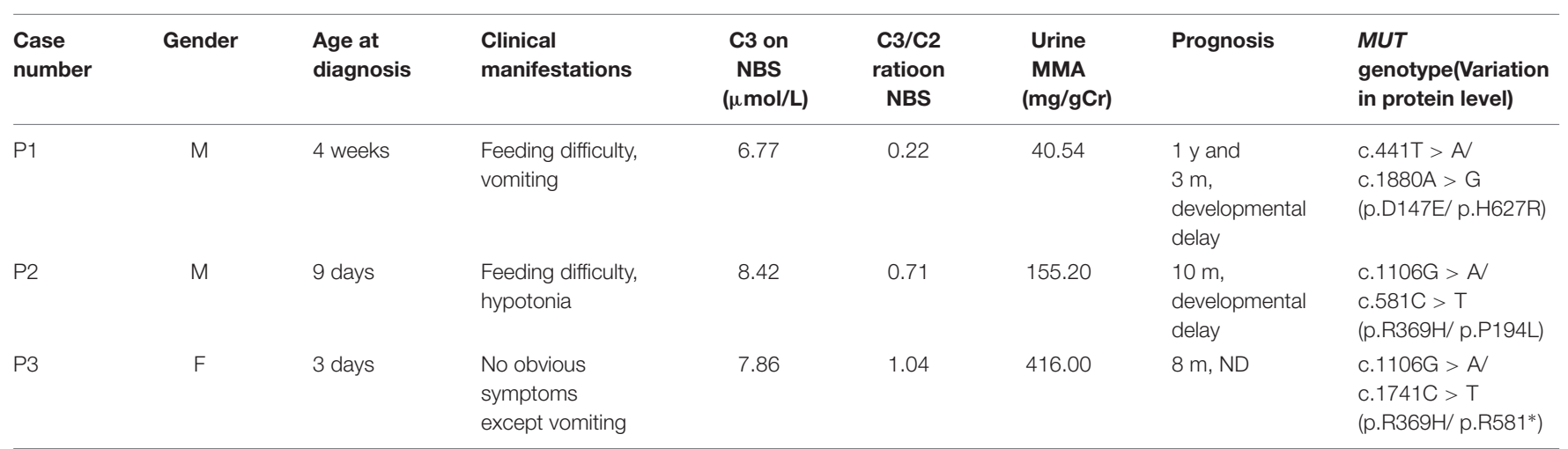

F: female; M: male; $y$, year; $m$, month; ND, normal development; ND, no data; Developmental delay for young children <4-6 years and intellectual impairment/disability for older children, while given the children are all $<2$ years old.

TABLE 4 | Median and range levels of C2, C3, and C3/C2 obtained from MMA screening.

\begin{tabular}{lcccr}
\hline Confirmed diagnosis & $\boldsymbol{n}$ & C2 Mean $($ Range $)(\boldsymbol{\mu ~ m o l} / \mathbf{L})$ & C3 Mean (Range) $(\boldsymbol{\mu ~ m o l} / \mathbf{L})$ & C3/C2 Mean $($ Range $)$ \\
\hline MMACHC mutation types & 11 & $17.52(7.31-33.71)$ & $7.05(4.04-8.80)$ & $0.64(0.24-1.57)$ \\
MUT mutation types & 3 & $16.65(7.53-30.64)$ & $7.68(6.77-8.42)$ & $0.66(0.22-1.04)$ \\
No mutations & 38 & $14.25(1.2-38.12)$ & $3.86(0.54-11.21)$ & $0.30(0.12-0.56)$ \\
\hline
\end{tabular}

\section{Accelerated Degradation of MMA Markers}

The accelerated degradation of MMA markers, including C2, C3, and $\mathrm{C} 3 / \mathrm{C} 2$, was analyzed while monitoring the effects of heat and humidity on newborn screening tests. Figures 4A,B present the changes in heat and humidity from spring to winter in two recent years in Xuzhou. The air temperature and precipitation were much higher in summer than in other seasons. C2 levels declined sharply during the summer in Xuzhou, but this decline was not observed in $\mathrm{C} 3$. However, the $\mathrm{C} 3 / \mathrm{C} 2$ ratios shown in Figure 4C were higher in summer than in other seasons, and this marker is crucial for identifying MMA by MS/MS. The thermal stability data for $\mathrm{C} 2$ revealed degradation at high air temperature with high humidity. The $\mathrm{C} 3 / \mathrm{C} 2$ ratio is considered the single index positive marker for MMA diagnosis, and the data in Figure 4D illustrate its volatility in different months, with higher values in summer, a time of high air temperature and humidity. In the following section, it will be argued that the dried blood spot collection conditions play an important role in newborn screening tests. Several hospital samples showed much higher values than others during the same period due to the high heat and humidity when collecting the blood spots from the infants. After the Cold-Chain Logistics system was implemented in the following year, the single index positive marker $\mathrm{C} 3 / \mathrm{C} 2$ sharply declined under the control range (Table 5). Indeed, the $P$ value illustrated the importance of changing the collection conditions.

\section{Mutation Analysis and Molecular Characteristics}

Nine different mutations in MMACHC (Figure 5 and Table 1) and five different mutations in MUT (Figure 6 and Table 3) were identified in 15 patients with MMA. Missense mutations were detected in the majority of cases and accounted for $63.6 \%$ of all MMACHC mutations (Figure 5A). Other mutations detected included insertions/deletions $(\sim 22.7 \%)$, duplications 

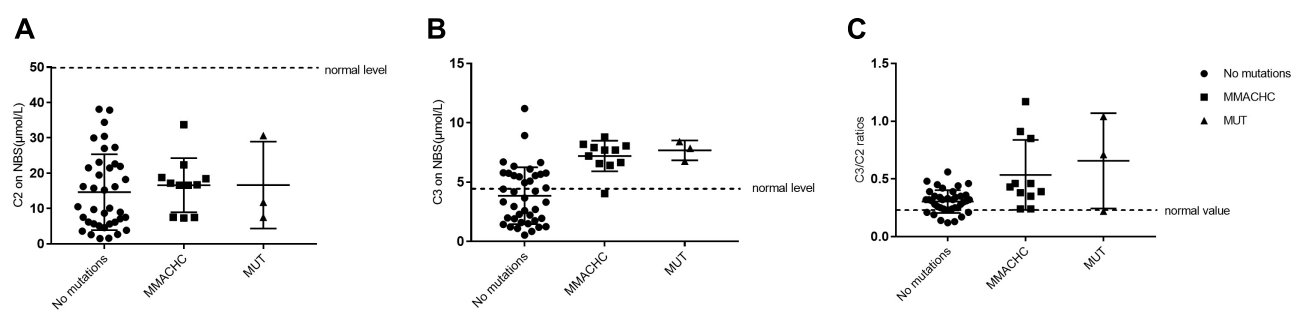

FIGURE 3 | Metabolite measurement in MMA compared to normal, MMACHC, and MUT patients. (A) The level of C2 on newborn screening. (B) The level of C3 on newborn screening. (C) The C3/C2 ratio on newborn screening.
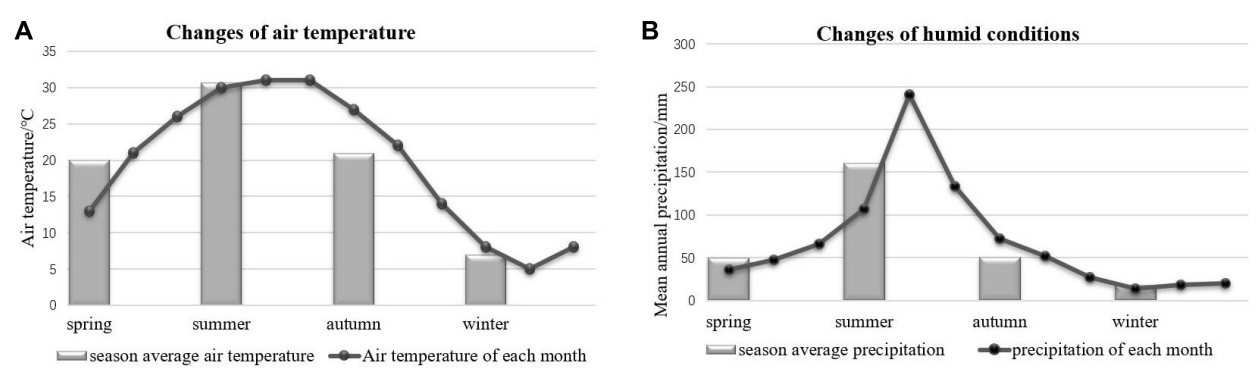

C

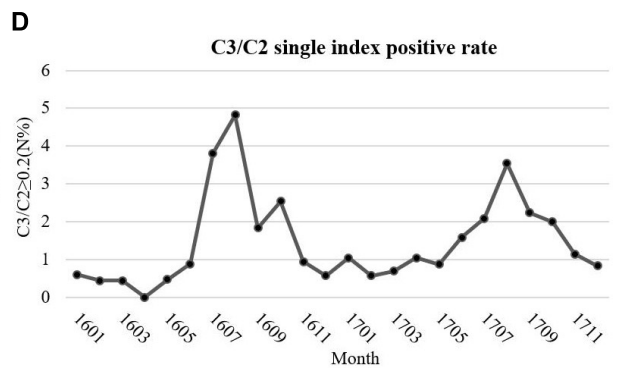

FIGURE 4 | The variation of environmental conditions and MMA markers. (A) The changes of air temperature. (B) The changes of humidity. (C) The changes of MMA markers in different seasons. (D) The single index positive rate of MMA.

TABLE 5 | The changes of ingle index positive rate marker C3/C2 in several hospitals in our study.

\begin{tabular}{|c|c|c|c|c|c|c|c|c|c|c|}
\hline Hospital name & Total samples (in 2 years) & \multicolumn{4}{|c|}{2016.08} & \multicolumn{4}{|c|}{2017.08} & $P$-value \\
\hline Suining People's Hospital & 10874 & 566 & 91.14 & 55 & 8.86 & 504 & 96.18 & 20 & 3.82 & 0.002 \\
\hline Xinyi People's Hospital & 9110 & 372 & 88.57 & 48 & 11.43 & 544 & 98.73 & 7 & 1.27 & \\
\hline
\end{tabular}

$(\sim 13.7 \%)$, splicing-related mutations and one initial codon mutation (Figure 5A). The c. 609G > A (p. W203*) mutation was the most frequently identified mutation and was detected in 8 alleles (6 patients, 6 families) (Figure 5B and Table 1). The second most commonly detected disease allele was c.482G $>$ A (p. R161Q) (4 alleles, 4 patients, and 4 families) (Figure 5B). Therefore, the two most frequent mutations found in our cohort were non-sense and missense mutations. A total of $11 \mathrm{clbC}$ patients had two mutations and one individual had only one mutation in the MMACHC gene (Table 1).
Of the previously reported mutations in the MUT gene in our center, five different ones were identified in this study. All of the mutations were missense or non-sense mutations. The missense mutation c.1106G > A (p. R369H) was identified in more than one unrelated patient (Figure 6C). All of the mutations shown in Figure 6B were found in exons 3 and 6 or 10 and 11, which are located in the N-terminal and C-terminal domains, respectively (Figure 6A). In addition, the three isolated MMA patients were diagnosed with compound heterozygous changes in the MUT gene (Table 3). 


\section{A Types of MMACHC mutations}

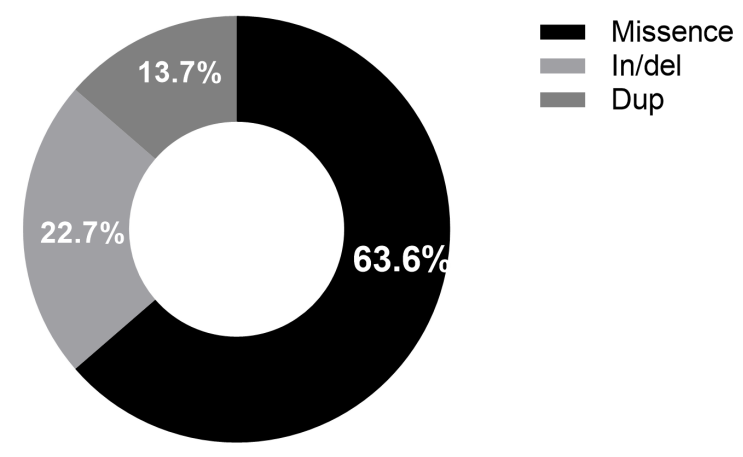

Total $=22$

B The MMACHC gene mutation types

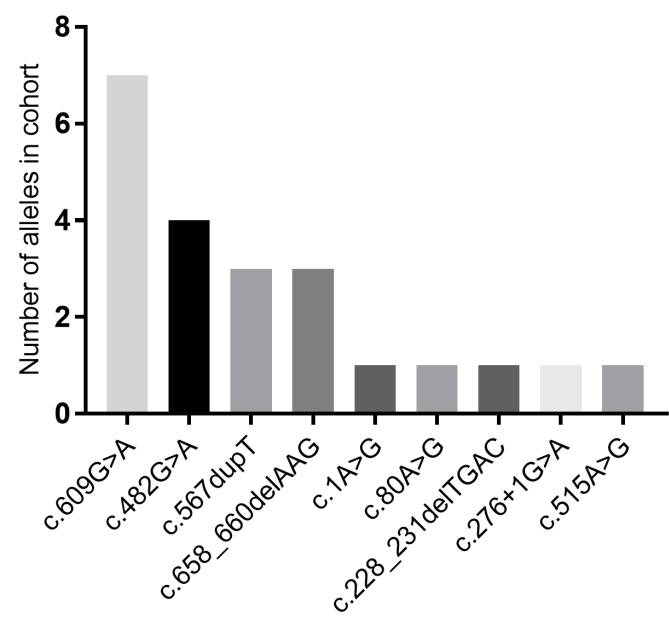

FIGURE 5 | Frequency of variant types and mutations in MMACHC gene. (A) Pie chart summarizing the types of MMACHC mutations. (B) Frequency of alleles that identified in cohort.

\section{DISCUSSION}

Newborn screening by MS/MS revealed a small increase in the blood $\mathrm{C} 3$ concentration and an increased C3/C2 ratio. To explain the variations in $\mathrm{C} 2, \mathrm{C} 3$, and $\mathrm{C} 3 / \mathrm{C} 2$, unaffected infants and MMA patients were compared during newborn screening. The usage of C2 significantly improved the screening sensitivity for MMA and reduced the number of false positives (Al-Dirbashi et al., 2016). The combination of abnormal C3 and C3/C2 results enabled the identification and referral of patients for further diagnosis (Armour et al., 2013). The presence of elevated MMA and homocysteine levels suggests an inborn error of cobalamin metabolism in clbC patients. In addition, MMA in the urine can result from both clbC disease and isolated MMA. According to our study, 236,368 newborns were screened, and 14 cases were diagnosed with MMA from November 2015 to December 2017 in Xuzhou. Thus, the incidence of MMA was approximately $1: 16,883$ in our area. The reported incidence of MMA ranges from $1: 115,000$ in Italy to $1: 169,000$ in Germany (Melo et al., 2011). However, there are no data available on the nationwide incidence of MMA in China. The estimated incidence of MMA was reported to be 1 in 26,000 infants in Beijing and Shanghai (Tu et al., 2013). In the Zhejiang Province, China, the incidence of MMA is $1: 64,708$ (Huang et al., 2011). In contrast, our study demonstrated an expectedly high incidence of MMA identified by MS/MS in Xuzhou.

Tandem mass spectrometry analysis of dried blood spots has become the predominant technique for newborn screening of inherited metabolic diseases. However, biomarkers in blood spots are susceptible to environmental conditions, such as heat and humidity. The most important and clinically relevant finding was that C2 levels declined sharply in the summer due to high air temperature and precipitations. This finding confirms with earlier observations that the storage of dried blood spots at room temperature in summer may accelerate C2 degradation, especially after blood collection in baby bathrooms. The stability of C2 and C3 is important for maintaining sample integrity for high-quality analysis and measurements of acylcarnitines in blood spots for MMA diagnosis (Adam et al., 2011). Ensuring optimal humidity and temperature conditions during dried blood spot transportation and storage is essential for maintaining sample integrity (Golbahar et al., 2014). To solve the above problems, the Cold-Chain Logistics system has been applied to improve dried blood spots storage conditions. Dried blood spot samples packaged with special sealed bags are stored in the $4^{\circ} \mathrm{C}$ constant temperature box, while transportation temperature is real-time monitored. Simultaneously, the effect of humidity and temperature can be avoided by the professional logistic method.

In the present study, we described the clinical, biochemical and molecular characteristics of a cohort of pediatric clbC patients treated at diagnosis. All of the patients were given hydroxocobalamin, folinic acid, levocarnitine and betaine following diagnosis. Of the $12 \mathrm{clbC}$ patients who carried mutant alleles in MMACHC, two were homozygous and 9 were compound heterozygous for the mutations. Only one heterozygous change was detected in another patient, suggesting that the second mutation may be in a non-coding region. We found 9 different mutations of $M M A C H C$, including c.609G > A, c.482G > A, c.567dupT, c.658_660delAAG, c. $1 \mathrm{~A}>\mathrm{G}$, c. $80 \mathrm{~A}>\mathrm{G}$, c.228_231delTGAC, c.276+1G > A, and c.515A > G (Liu et al., 2010; Wang et al., 2010). The most common mutation was $\mathrm{c} .609 \mathrm{G}>\mathrm{A}$, which reportedly has the highest incidence in Chinese clbC patients (Han et al., 2016). Four patients were heterozygous and two patients were homozygous for this mutation. The second most frequent mutation, c. $482 \mathrm{G}>\mathrm{A}$, was detected in four patients $(33.3 \%)$. In comparison, c. $276+1 \mathrm{G}>\mathrm{A}$ was reported as the most frequent mutation in European populations with clbC disease (LernerEllis et al., 2009). Furthermore, we attempted to correlate the genotype with the phenotype in clbC disease. Presentation can occur during the neonatal period as an acute metabolic crisis or even death, as reported for case 3 in our center. 


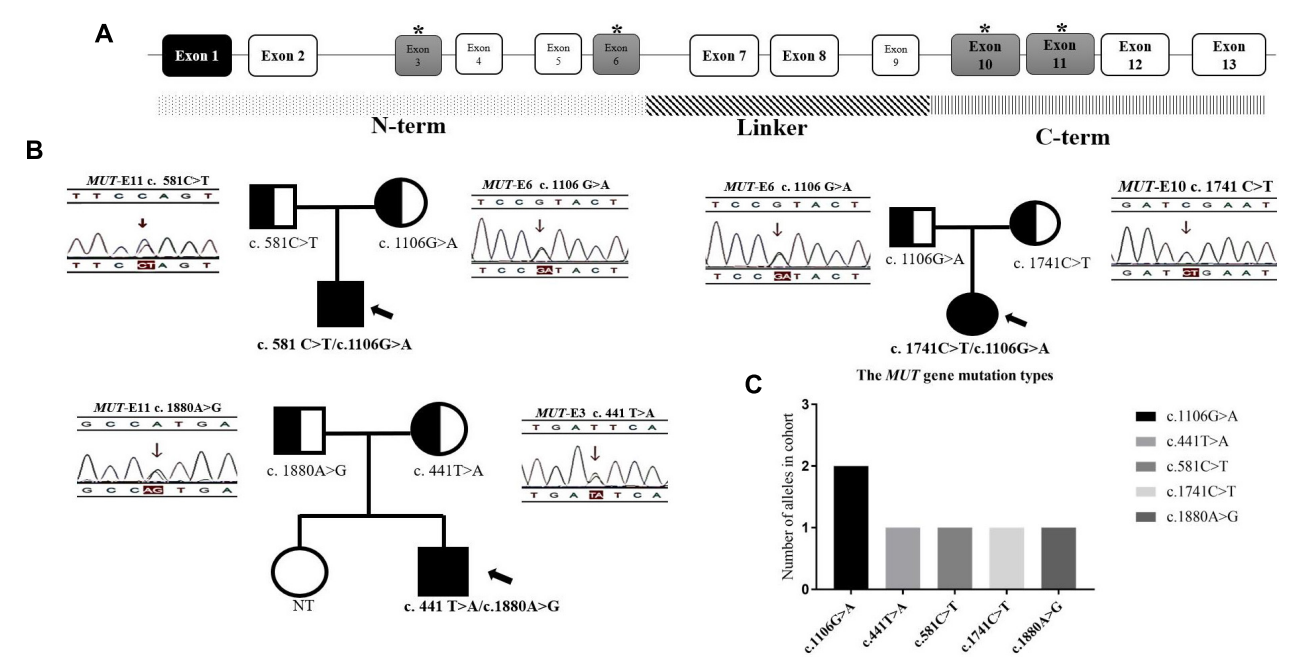

FIGURE 6 | The distribution of mutations found in 3 mut-MMA patients. (A) The structure of MUT gene. (B) The family genetic map of three mut-MMA patients. (C) The frequency of MUT alleles. * marked the exons/locations of the mutations identified upon the structure of MUT gene.

The compound heterozygous mutations c.276+1G $>\mathrm{A}$ and c.658_660delAAG reportedly cause acute metabolic crisis at an early age. Moreover, insidious developmental delay without metabolic illness, or neurological deterioration, can also occur in a previously healthy child, adolescent or adult (Fischer et al., 2014). Seven patients who received treatment presented with various clinical manifestations, including intellectual disability or impairment (Kölker et al., 2015; Levenson, 2015). Case 2, who died a few months after birth, had the compound heterozygous mutation c.1A > G and c.658_660delAAG, suggesting that infant presentation should correlate with the presence of two mutations. Surprisingly, case 12, who was treated with only hydroxocobalamin due to the homozygous mutation c.609G $>$ A, did not present with obvious developmental problems (Wang et al., 2010), whereas case 4, who had the compound heterozygous mutation c.609G > A and c.228_231delTGAC, had severe developmental delay, indicating that the c.228_231delTGAC mutation appears to be correlated with a more serious phenotype. What is not yet clear is the impact of these biochemical results on clbC individuals with only one mutation as Case 6. To date, there has been some reliable evidence that such compound heterozygotes might exit another mutation for a promoter epimutation, resulting from $P R D X 1$ mutations that force antisense transcription of MMACHC (Guéant et al., 2018). Although these represent the tip of the iceberg of potential reasons, indeed, it might be the possible explanation of the very interesting new syndrome of the patients with elevated tHcy. However, the number of patients in our study was limited, the information was not sufficient, and exact genotype-phenotype correlations cannot be established. Further investigations that examine environmental, ethnic and health condition including the retinal changes and individual genetic variations are warranted (Carrillo-Carrasco et al., 2012).

Three isolated MMA patients underwent MUT mutation analysis. Sequence analysis identified 5 different mutations of the diseased alleles, namely, c.441T $>\mathrm{A}, \mathrm{c} .581 \mathrm{C}>\mathrm{T}$, c.1106G > A, c.1741C > T, and c.1880A > G, and all three patients had compound heterozygous mutations. The presence of CpG dinucleotides, namely, c.1106G > A and c.1741C > T in exons 6 and 10, respectively, was not reported to be population specific (Han L.S. et al., 2015). The other three mutations were located in exons 3 and 11 . With respect to genotype-phenotype correlations, the limited number of patients included in our study, frequency of compound heterozygotes and lack of enzymatic detections made it difficult to assess the relationship between gene mutations and clinical manifestation. Patients P2 and P3, identified during the newborn screening with higher urinary MMA than P1, were both heterozygous for c.1106G > A. However, most patients homozygous for this mutation experience neonatal disease onset (Lempp et al., 2007). The MUT gene missense mutations in our study were all in the N-terminal and C-terminal domains (Forny et al., 2016; Han et al., 2017). This finding is consistent with the functional domain of MCM, and indicates that all the native amino acid residues involved are highly/fully conserved and likely to impact the structural stability of MCM (Acquaviva et al., 2005; Sakamoto et al., 2007; Zsengellér et al., 2014). Study limitations make an overall conclusion about MMA mutation types detection extremely difficult.

In conclusion, this is the first clinical cohort description focused on the inclusion of MMA as a target disorder for population-based newborn screening. MMA affects individuals worldwide but is an especially common inherited metabolic disease in our region. Based on our knowledge of MMA, patients should receive treatment as soon as possible after birth. No correlation was established between the associated mutations and clinical manifestations. Nevertheless, the molecular characteristics suggest the need for accurate and convenient genetic counseling for MMA patients and early prenatal diagnosis for high-risk families (Hu et al., 2018). Thus, it 
is critical to increase the coverage of newborn screening to allow early detection and treatment of MMA and combined MMA and homocystinuria patients.

\section{ETHICS STATEMENT}

This study was carried out in accordance with the recommendations of 'Expanding screening programs for neonatal diseases, Xuzhou Health and Family Planning Committee' with written informed consent from all subjects. All subjects gave written informed consent in accordance

\section{REFERENCES}

Acquaviva, C., Benoist, J. F., Pereira, S., Callebaut, I., Koskas, T., Porquet, D., et al. (2005). Molecular basis of methylmalonyl-CoA mutase apoenzyme defect in 40 European patients affected by mut0 and mut-forms of methylmalonic acidemia: identification of 29 novel mutations in the MUT gene. Hum. Mutat. 25, 167-176. doi: 10.1002/humu.20128

Adam, B. W., Hall, E. M., Sternberg, M., Lim, T. H., Flores, S. R., O’Brien, S., et al. (2011). The stability of markers in dried-blood spots for recommended newborn screening disorders in the United States. Clin. Biochem. 44, 14451450. doi: 10.1016/j.clinbiochem.2011.09.010

Al-Dirbashi, O. Y., McIntosh, N., and Chakraborty, P. (2016). Quantification of 2-methylcitric acid in dried blood spots improves newborn screening for propionic and methylmalonic acidemias. J. Med. Screen. 24, 58-61. doi: 10. 1177/0969141316645824

Armour, C. M., Brebner, A., Watkins, D., Geraghty, M. T., Chan, A., and Rosenblatt, D. S. (2013). A patient with an inborn error of vitamin B12 metabolism (cblF) detected by newborn screening. Pediatrics 132, e257-e261. doi: 10.1542/peds.2013-0105

Carrillo-Carrasco, N., Chandler, R. J., and Venditti, C. P. (2012). Combined methylmalonic acidemia and homocystinuria, cblC type. I. Clinical presentations, diagnosis and management. J. Inherit. Metab. Dis. 35, 91-102. doi: 10.1007/s10545-011-9364-y

Fischer, S., Huemer, M., Baumgartner, M., Deodato, F., Ballhausen, D., Boneh, A., et al. (2014). Clinical presentation and outcome in a series of 88 patients with the cblC defect. J. Inherit. Metab. Dis. 37, 831-840. doi: 10.1007/s10545-014-9687-6

Forny, P., Schnellmann, A. S., Buerer, C., Lutz, S., Fowler, B., Froese, D. S., et al. (2016). Molecular genetic characterization of 151 Mut-type methylmalonic aciduria patients and identification of 41 novel mutations in MUT. Hum. Mutat. 37, 745-754. doi: 10.1002/humu.23013

Golbahar, J., Altayab, D., and Carreon, E. (2014). Short-term stability of amino acids and acylcarnitines in the dried blood spots used to screen newborns for metabolic disorders. J. Med. Screen. 21, 5-9. doi: 10.1177/0969141314525367

Guéant, J.-L., Chéry, C., Oussalah, A., Nadaf, J., Coelho, D., Josse, T., et al. (2018) A PRDX1 mutant allele causes a $M M A C H C$ secondary epimutation in cblC patients. Nat. Commun. 9:67. doi: 10.1038/s41467-017-02306-5

Han, B., Cao, Z., Tian, L., Zou, H., Yang, L., Zhu, W., et al. (2016). Clinical presentation, gene analysis and outcomes in young patients with earlytreated combined methylmalonic acidemia and homocysteinemia (cblC type) in Shandong province, China. Brain Dev. 38, 491-497. doi: 10.1016/j.braindev. 2015.10.016

Han, L. S., Huang, Z., Han, F., Wang, Y., Gong, Z. W., and Gu, X. F. (2017). Eight novel MUT loss-of-function missense mutations in Chinese patients with isolated methylmalonic academia. World J. Pediatr. 13, 381-386. doi: 10.1007/ s12519-016-0085-z

Han, L.S., Huang, Z., Han, F., Ye, J., Qiu, W.-J., Zhang, H.-W., et al. (2015). Clinical features and MUT gene mutation spectrum in Chinese patients with isolated methylmalonic acidemia: identification of ten novel allelic variants. World J. Pediatr. 11, 358-365. doi: 10.1007/s12519-015-0043-1

Han, L., Wu, S., Han, F., and Gu, X. (2015). Insights into the molecular mechanisms of methylmalonic acidemia using microarray technology. Int. J. Clin. Exp. Med. $8,8866-8879$. with the Declaration of Helsinki. The protocol was approved by the 'Xuzhou Health and Family Planning Committee'.

\section{AUTHOR CONTRIBUTIONS}

WZ and MG designed the experiments. WZ and HL carried out the experiments. WZ and CW analyzed the experimental results. XW worked as a clinical diagnosis and treatment doctor. HL assisted with collating clinical data. WZ and HL wrote the manuscript.

Hörster, F., Baumgartner, M. R., Viardot, C., Suormala, T., Burgard, P., Fowler, B., et al. (2007). Long-term outcome in methylmalonic acidurias is influenced by the underlying defect (mut0, mut| [minus]|, cblA, cblB). Pediatr. Res. 62, 225-230. doi: 10.1203/PDR.0b013e3180a $0325 \mathrm{f}$

Hu, S., Mei, S., Liu, N., and Kong, X. (2018). Molecular genetic characterization of $c b l C$ defects in 126 pedigrees and prenatal genetic diagnosis of pedigrees with combined methylmalonic aciduria and homocystinuria. BMC Med. Genet. 19:154. doi: 10.1186/s12881-018-0666-x

Huang, X. W., Yang, J. B., Tong, F., Yang, R. L., Mao, H. Q., Zhou, X. L., et al. (2011). Screening for neonatal inborn errors of metabolism by electrospray ionization-tandem mass spectrometry and follow-up. Zhonghua $\mathrm{Er} \mathrm{Ke} \mathrm{Za} \mathrm{Zhi}$ $49,765-770$.

Huemer, M., Scholl-Bürgi, S., Hadaya, K., Kern, I., Beer, R., Seppi, K., et al. (2014). Three new cases of late-onset $c b l C$ defect and review of the literature illustrating when to consider inborn errors of metabolism beyond infancy. Orphanet J. Rare Dis. 9:161. doi: 10.1186/s13023-014-0161-1

Kölker, S., Garcia-Cazorla, A., Valayannopoulos, V., Lund, A., Burlina, A., SykutCegielska, J., et al. (2015). The phenotypic spectrum of organic acidurias and urea cycle disorders. Part 1: the initial presentation. J. Inherit. Metab. Dis. 38, 1041-1057. doi: 10.1007/s10545-015-9839-3

Ktena, Y. P., Paul, S. M., Hauser, N. S., Sloan, J. L., Gropman, A., Manoli, I., et al. (2015). Delineating the spectrum of impairments, disabilities, and rehabilitation needs in methylmalonic acidemia (MMA). Am. J. Med. Genet. A 167A, 20752084. doi: 10.1002/ajmg.a.37127

Lempp, T. J., Suormala, T., Siegenthaler, R., Baumgartner, E. R., Fowler, B., Steinmann, B., et al. (2007). Mutation and biochemical analysis of 19 probands with mut0 and 13 with mut- methylmalonic aciduria: identiWcation of seven novel mutations. Mol. Genet. Metab. 90, 284-290. doi: 10.1016/j.ymgme.2006. 10.002

Lerner-Ellis, J. P., Anastasio, N., Liu, J., Coelho, D., Suormala, T., Stucki, M., et al. (2009). Spectrum of mutations in MMACHC, allelic expression, and evidence for genotype-phenotype correlations. Hum. Mutat. 30, 1072-1081. doi: 10.1002/humu.21001

Levenson, D. (2015). Medical foods prescribed to treat methylmalonic acidemia linked with adverse outcomes for some patients: studies explore impact of unbalanced amino acid formulation on growth, brain development. Am. J. Med. Genet. A 167A, ix-x.

Liu, M.-Y., Yang, Y.-L., Chang, Y.-C., Chiang, S.-H., Lin, S.-P., Han, L.-S., et al. (2010). Mutation spectrum of MMACHC in Chinese patients with combined methylmalonic aciduria and homocystinuria. J. Hum. Genet. 55, 621-626. doi: 10.1038/jhg.2010.81

Melo, D. R., Kowaltowski, A. J., Wajner, M., and Castilho, R. F. (2011). Mitochondrial energy metabolism in neurodegeneration associated with methylmalonic acidemia. J. Bioenerg. Biomembr. 43, 39-46. doi: 10.1007/ s10863-011-9330-2

Obeid, R., Fedosov, S. N., and Nexo, E. (2015). Cobalamin coenzyme forms are not likely to be superior to cyano- and hydroxyl-cobalamin in prevention or treatment of cobalamin deficiency. Mol. Nutr. Food Res. 59, 1364-1372. doi: 10.1002/mnfr.201500019

Pastore, A., Martinelli, D., Piemonte, F., Tozzi, G., Boenzi, S., and Di Giovamberardino, G. (2014). Glutathione metabolism in cobalamin deficiency 
type C (cblC). J. Inherit. Metab. Dis. 37, 125-129. doi: 10.1007/s10545-0139605-3

Peng, G., Shen, P., Gandotra, N., Le, A., Fung, E., Jelliffe-Pawlowski, L., et al. (2018). Combining newborn metabolic and DNA analysis for second-tier testing of methylmalonic acidemia. Genet. Med. doi: 10.1038/s41436-018-0272-5 [Epub ahead of print].

Radmanesh, A., Zaman, T., Ghanaati, H., Molaei, S., Robertson, R. L., and Zamani, A. A. (2008). Methylmalonic acidemia: brain imaging findings in 52 children and a review of the literature. Pediatr. Radiol. 38, 1054-1061.

Richard, E., Gallego-Villar, L., Rivera-Barahona, A., Oyarzabal, A., Perez, B., Rodriguez-Pombo, P., et al. (2018). Altered redox homeostasis in branchedchain amino acid disorders, organic acidurias, and homocystinuria. Oxid. Med. Cell. Longev. 2018:1246069. doi: 10.1155/2018/1246069

Sakamoto, O., Ohura, T., Matsubara, Y., Takayanagi, M., and Tsuchiya, S. (2007). Mutation and haplotype analyses of the MUT gene in Japanese patients with methylmalonic acidemia. J. Hum. Genet. 52, 48-55. doi: 10.1007/s10038-0060077-2

Tu, W.-J., Chen, H., and He, J. (2013). Methylmalonic aciduria: newborn screening in mainland China? J. Pediatr. Endocrinol. Metab. 26, 399-400. doi: 10.1515/ jpem-2012-0276

Wang, F., Han, L., Yang, Y., Gu, X., Ye, J., Qiu, W., et al. (2010). Clinical, biochemical, and molecular analysis of combined methylmalonic acidemia and hyperhomocysteinemia (cblC type) in China. J. Inherit. Metab. Dis. 33(Suppl. 3), S435-S442. doi: 10.1007/s10545-010-9217-0

Weisfeld-Adams, J. D., Bender, H. A., Miley-Akerstedt, A., Frempong, T., Schrager, N. L., Patel, K., et al. (2013). Neurologic and neurodevelopmental phenotypes in young children with early-treated combined methylmalonic acidemia and homocystinuria, cobalamin C type. Mol. Genet. Metab. 110, 241-247. doi: 10.1016/j.ymgme.2013.07.018
Weisfeld-Adams, J. D., Morrissey, M. A., Kirmse, B. M., Salveson, B. R., Wasserstein, M. P., McGuire, P. J., et al. (2010). Newborn screening and early biochemical follow-up in combined methylmalonic aciduria and homocystinuria, cblC type, and utility of methionine as a secondary screening analyte. Mol. Genet. Metab. 99, 116-123. doi: 10.1016/j.ymgme.2009. 09.008

Worgan, L. C., Niles, K., Tirone, J. C., Hofmann, A., Verner, A., Sammak, A., et al. (2006). Spectrum of mutations in mut methylmalonic acidemia and identification of a common Hispanic mutation and haplotype. Hum. Mutat. 27, 31-43. doi: 10.1002/humu.20258

Yu, H. C., Sloan, J. L., Scharer, G., Brebner, A., Quintana, A. M., Achilly, N. P., et al. (2013). An X-linked cobalamin disorder caused by mutations in transcriptional coregulator HCFC1. Am. J. Hum. Genet. 93, 506-514. doi: 10.1016/j.ajhg.2013. 07.022

Zsengellér, Z. K., Aljinovic, N., Teot, L. A., Korson, M., Rodig, N., Sloan, J. L., et al. (2014). Methylmalonic acidemia: a megamitochondrial disorder affecting the kidney. Pediatr. Nephrol. 29, 2139-2146. doi: 10.1007/s00467-014-2847-y

Conflict of Interest Statement: The authors declare that the research was conducted in the absence of any commercial or financial relationships that could be construed as a potential conflict of interest.

Copyright (c) 2019 Zhou, Li, Wang, Wang and Gu. This is an open-access article distributed under the terms of the Creative Commons Attribution License (CC BY). The use, distribution or reproduction in other forums is permitted, provided the original author(s) and the copyright owner(s) are credited and that the original publication in this journal is cited, in accordance with accepted academic practice. No use, distribution or reproduction is permitted which does not comply with these terms. 